\title{
INÍCIO E FIM DE MEMÓRIAS PÓSTUMAS DE BRÁS CUBAS: CONEXÕES COM A BÍBLIA, A ESCRAVIDÃO E A RETÓRICA
}

\section{PAULO SÉRGIO DE PROENÇA}

Universidade da Integração Internacional da Lusofonia Afro-Brasileira São Francisco do Conde, Bahia, Brasil

Resumo: Início e fim são posições estratégicas. O objetivo deste trabalho é avaliar o papel estrutural desses limites narrativos nas Memórias póstumas de Brás Cubas, em que as Escrituras estão presentes tanto na abertura quanto no fecho. As principais fontes teóricas são Del Lungo (2003), Bakhtin (1987), Hutcheon (1987), Fávero (1994), Duarte (2008), Aristóteles (2005) e Quintiliano (2015). Machado fez livre uso das fontes bíblicas, de forma paródica e carnavalesca, para denunciar os desarranjos da sociedade de seu tempo, como a escravidão, em convergência com assumido pessimismo; o autor tem consciência do papel estrutural das partes da narrativa romanesca e as maneja com habilidade retórica e ficcional.

Palavras-chave: Memórias póstumas; Início; Fim; Bíblia; Retórica.

\section{BEGINNING AND ENDING OF THE POSTHUMOUS MEMOIRS OF BRÁS CUBAS: CONNECTIONS WITH THE BIBLE, SLAVERY, AND RHETORIC}

Abstract: Beginning and end are strategic positions. The purpose of this work is to evaluate the structural role of these narrative limits in The Posthumous Memoirs of Brás Cubas, where the presence of the Scriptures is both at the opening and closing of the novel. The main theoretical sources for this article include Del Lungo (2003), Bakhtin (1987), Hutcheon (1987), Fávero (1994), Duarte (2008), Aristotle (2005) and Quintilian (2015). Machado made free use of biblical sources, in a parodic and carnivalesque way, to denounce the dysfunctional aspects of society in his time, such as slavery, in convergence with assumed pessimism; the author is aware of the structural role of the parts of the novel's narrative and handles them with rhetorical and fictional skill.

Keywords: The Posthumous Memoirs of Brás Cubas; Beginning; End; Bible; Rhetoric. 


\section{Considerações iniciais}

Início e fim são posições estratégicas em qualquer peça comunicativa, pontas que unem de forma coesiva uma sequência, são a porta de entrada e de saída no universo romanesco - o primeiro e o último contato entre narrador e narratários. Daí a importância desses limites e a necessidade de percepção, inclusive sob o ponto de vista retórico.

Assim, propõe-se focar aspectos relativos à importância do começo (incipit) e do fim no romance Memórias póstumas de Brás Cubas. Curiosamente, essas partes bem indicam pistas para a interpretação do romance, que apresenta características interessantes quanto à natureza literária dessas posições; nelas há menções à Bíblia, de forma paródicocarnavalesca e de forma pessimista em um final construído em negativas.

A abordagem teórica dos revestimentos literário e retórico do começo e do fim do romance seguirá Del Lungo (2003), que estuda o incipit romanesco; Bakhtin (1987), para considerações sobre carnavalização; Hutcheon (1987) no que concerne à paródia; Aristóteles (2005) e Quintiliano (2015) para a dimensão retórica - além de críticos que se ocuparam do estudo da obra machadiana.

Machado de Assis tinha domínio do papel estrutural das partes que compunham as sequências e do conjunto do material romanesco e sabia extrair desses elementos o que podiam oferecer, neles projetando sua criatividade literária.

\section{O começo: diálogo carnavalesco e paródico com a Bíblia}

O começo do romance estabelece conexões com dois personagens bíblicos: Moisés (mais diretamente) e Jesus (mais indiretamente) são evocados; aquele, em tom carnavalesco; este, em tom paródico.

Já no primeiro parágrafo, Brás Cubas cita o Pentateuco, diz que se sente mais engenhoso do que Moisés, por narrar a morte no começo. De fato, a Bíblia autoriza alguém a contar a própria morte; e, se Moisés faz isso, Brás poderia também fazer, ainda mais por ser um defunto autor. ${ }^{1}$ Em seguida, há evocações paródicas a Jesus.

\footnotetext{
${ }^{1}$ A condição do defunto autor não é tão simples. A dedicatória do livro é um epitáfio, o livro é um sepulcro. Nos primeiros capítulos há doença, agonia, morte, enterro, decomposição. O defunto autor sugere universalidade, pela esfera filosófico-metafísica assegurada pela presença da morte, de Deus etc.
} 
Quanto à dimensão carnavalesca, Mikhail Bakhtin liga a produção literária de Rabelais a fontes populares, com a valorização do riso e da cultura da praça pública, características presentes nas festas religiosas da Idade Média, cujos ritos ofereciam visão não oficial do mundo e das relações humanas, exterior à Igreja e ao Estado; também aspectos sérios e cômicos se misturavam, numa dualidade ambivalente, com fusão do alto e do baixo, do feio e do bonito, do conveniente e do não conveniente. A esse fenômeno Bakhtin dá o nome de "realismo grotesco" (DISCINI, 2006).

Ambivalência, inversão de posições e valores, riso aberto que vence o medo, inacabamento e renovação da vida, valorização do baixo corporal, do ato de comer, do jogo linguístico-paródico - tudo isso está presente no realismo grotesco, cuja topografia se torna estratégica. O alto e o baixo possuem um sentido espacial. A terra é túmulo e, ao mesmo tempo, ventre e ressurreição. Ainda que de forma indireta, essa ideia está presente no início das Memórias póstumas, mais precisamente na ideia de que a narrativa é vitória sobre a morte. Há nisso estímulo para concepção ambivalente do realismo grotesco, para o qual "a degradação cava o túmulo corporal para dar lugar a um novo nascimento [...]” (BAKHTIN, 1987, p. 19).

O riso se torna revolucionário na justaposição à seriedade, impregnada por elementos de medo (fraqueza, resignação, mentira, hipocrisia) ou de violência (intimidação, ameaças e interdições). $O$ poder se associa naturalmente à seriedade que intimida e proíbe, mente e distorce. $\mathrm{O}$ riso incide sobre uma dimensão não somente humorística, mas sobretudo renovadora, justamente por ridicularizar o sério. Da combinação desses elementos, no caso das Memórias, resulta a desorganização narrativa, em desestruturação estético-ideológica. E tudo isso já sugerido no início da narrativa.

A carnavalização não é apenas motivo estético para a construção do romance, ela assume características estilísticas, reforçadas na progressão da narração e na forma com que peripécias são retratadas. É por isso que o narrador define como ébrio seu estilo de narrar, contrariando as expectativas de seu auditório, acostumado a narrativas de progressão linear. ${ }^{2}$

Roberto Schwarz (2000) vê nisso a indicação de uma referência principal, o enraizamento no Brasil; para ele, o defunto autor é uma provocação. E esse ar fúnebre (e maroto) está no incipit.

2 Schwarz (2000) reconhece a relevância da materialidade da narração; em Machado a forma corresponde ao funcionamento da sociedade. Para o crítico, o narrador das Memórias caracteriza-se pela arbitrariedade própria da classe social por ele representada. Souza (1998) refuta essa ideia e propõe que as voltas do narrador merecem outra abordagem, inspirada no teatro, que possibilita a representação de múltiplos papéis, na recuperação etimológica de mímesis. 
A paródia, por sua vez, é um dos meios pelos quais pode se manifestar a carnavalização. É o que acontece no início do romance, na cena do enterro. Brás Cubas morreu numa sexta-feira, às duas horas da tarde ${ }^{3}$, quando chovia. Segundo a narrativa da paixão, em Jerusalém espessas trevas cobriram o céu (Marcos 14.33; Lucas 23.44-45). Outro detalhe: onze amigos acompanhavam o enterro de Brás Cubas. Quando Jesus morreu, havia onze discípulos, pois Judas não mais fazia parte do grupo. Assistiram ao enterro três mulheres: a irmã Sabina, a filha dela e uma sobrinha de Virgília; nova coincidência, pois havia exatamente três mulheres no enterro de Jesus (João 19.25): Maria (a mãe de Jesus), a irmã de sua mãe (Maria, mulher de Clopas) e Maria Madalena (MARIA, 2007).

Mais: Brás tem ressurreição na narrativa que empreende do além; nesse jogo fantástico do post mortem, continua a falar, dotado de características divinas. Mais ainda: a causa mortis foi o pretenso ato heroico que tinha por objetivo salvar a humanidade da melancolia; mais um traço de parentesco com Jesus, evocado de forma paródica, arrevesada, brincalhona (PROENÇA, 2011, p. 206).

A paródia é expressão que mobiliza trocas de forma criativa, e a:

[...] marca fundamental da paródia é o caráter polifônico, que a faz absorver um texto para depois repeli-lo, recriando-o num modelo próprio. Ela não se reduz a uma mera repetição do texto primitivo, mas soa como um eco deformado e as palavras do Outro se revestem de algo novo, tornam-se bivocais. (FÁVERO, 1994, p. 60)

No realismo grotesco as paródias eram livres: ocupavam-se do culto, do dogma, da Bíblia. Um de seus efeitos inconfundíveis é o riso carnavalesco ambivalente, principalmente quando o alvo era religioso.

Para Hutcheon, a paródia é resultado da mescla de elogio e censura, ato crítico de reavaliação e acomodação. Paródia não é "aquela imitação ridicularizadora mencionada nas definições dos dicionários populares" (FÁVERO, 1994, p. 60), embora não deixe de ser um fenômeno de imitação, com o qual compartilha o recurso de incorporação em sua organização formal; tem distância irônica, o que sugere alargamento do conceito; não se trata apenas de imitação, mas de apropriação textual com revisão crítica. Exige participação do leitor, na apreensão interpretativa. Hutcheon busca elementos etimológicos para propor uma definição:

\footnotetext{
${ }^{3}$ Segundo os evangelhos, Jesus morreu na hora nona, em que havia oração no templo de Jerusalém. Pelo sistema de contagem das horas então utilizado, isso corresponde a três horas da tarde.
} 
A maioria dos teóricos da paródia remonta à raiz etimológica do termo ao substantivo grego parodia, que quer dizer "contracanto", e ficam-se por aí [...]. A natureza textual ou discursiva da paródia (por oposição à sátira) é evidente no elemento odos da palavra, que significa canto. $\mathrm{O}$ prefixo para tem dois significados sendo geralmente mencionado apenas um deles - o de "contra" ou "oposição". Desta forma, a paródia torna-se uma oposição ou contraste entre textos. Este é, presumivelmente, o ponto de partida formal para a componente de ridículo pragmático habitual da definição: um texto é confrontado com outro, com a intenção de zombar dele ou de o tornar caricato [...]. No entanto, para em grego também pode significar "ao longo de" e, portanto, existe uma sugestão de um acordo ou intimidade, em vez de um contraste. (HUTCHEON, 1989, p. 48)

A paródia precisa ter reconhecidos os elementos de repetição e diferença. A diferença nasce da distância crítica marcada pela ironia. Ela se projeta no eixo que combina continuidade e mudança. Não é simples citação (apesar de agregar prestígio e autoridade); ela aproxima e distancia, pela ironia e ambiguidade, marcando diferenças. Contudo, não há somente repetição com diferença crítica: "A paródia é, ao mesmo tempo, duplicação textual (que unifica e reconcilia) e diferenciação (que coloca em primeiro plano a oposição irreconciliável entre textos e entre texto e "mundo)" (HUTCHEON, 1989, p. 129).

O efeito paródico do começo das Memórias indica que Brás via-se como Cristo-benfeitor, que morre por causa de esforço em prol da humanidade, para salvá-la. Esse Cristo-paródico, risível, representa a visão de mundo que via na cristianização o meio de salvar os homens. Contudo, o efeito produzido é diverso, desvelador dos mecanismos pelos quais esse processo se configura o que é perceptível ao longo da narrativa, mas já inscrito no começo.

Desde o início é notada a liberdade com que o material bíblico é tratado, fruto de uma consciente e autônoma incorporação da tradição, como atestam paródias que livremente recriam e ressignificam conteúdos. Essa liberdade tem precedentes históricos e literários na sátira menipeia, sendo Luciano de Samósata o principal representante. Dele, Machado tinha em sua biblioteca as obras completas em francês (JOBIM, 2001).

Sá Rego sustenta que a utilização da paródia é característica da tradição da sátira menipeia, inaugurada por Luciano de Samósata (115[120?]-181?), que inspirou muitos escritores, dentre os quais Rabelais, Swift e o próprio Machado. Defendia o riso filosófico; escreveu o Diálogo dos Mortos, em que 
reis e nobres, depois de mortos, viram mendigos. Um personagem frequente nessa obra é Menipo, discípulo de Diógenes, que viveu no século IV a.C. em Gadara (Síria) (JOBIM, 2001). Assim nasce a "sátira menipeia", que fez da religião e da filosofia epicurista os principais alvos de suas críticas (PROENÇA, 2011, p. 138).

Passemos agora ao incipit, importante elemento da técnica narrativa romanesca, que delimita palavras inaugurais. O termo deriva de manuscritos medievais, em que apontava o começo de um novo texto, apresentava o nome do autor, seu lugar de proveniência e outros elementos paratextuais.

O começo de um romance é uma tomada de posição, um momento decisivo, a explicitude primeira de um ato criador; serve para "orientar e legitimar o texto [...] construir um universo ficcional, fornecer informações sobre o enredo; ou seja, dirigir a leitura” (DEL LUNGO, 2003, p. 14).

O incipit envolve estratégia de abertura que realiza a passagem à ficção, além de servir de meio para seduzir o leitor. Uma de suas funções é orientar a leitura; assim, remete a um "fora do texto", a um saber comum partilhado pelo autor e pelos leitores, numa projeção intertextual e interdiscursiva ${ }^{4}$ indispensável à estratégia de composição ficcional, justamente por seu valor de orientação e de guia que regula as expectativas do leitor.

Del Lungo destaca que ele "orienta um percurso narrativo, um eixo de interesse romanesco (pela criação e resolução de enigmas), uma disposição de espera (pela exposição de índices e de sinais do desenlace)" (DEL LUNGO, 2003, p. 50). O incipit concentra, em forma cifrada e sintética, lances e desdobramentos narrativos e deve ser considerado "não somente um lugar de orientação, mas também uma referência constante na sequência, como um primeiro acorde ao qual deve se reportar uma sinfonia inteira" (DEL LUNGO, 2003, p. 55).

O início das Memórias póstumas parece sugerir livre e polêmica apropriação do texto bíblico, comandada por motivações do medieval carnavalesco e da paródia; isso indica um caminho, uma isotopia de leitura que deve comandar a leitura. Percebida essa senha, fica mais fácil entender certos movimentos da progressão textual.

\footnotetext{
${ }^{4}$ Usamos aqui os termo "autor" e "leitor" em vez de "narrador" e "narratário" (autor não corresponde a narrador), que são preferíveis pelo fato de não termos acesso ao autor nem aos leitores como seres de autonomia. Pode-se presumir a existência de narrador e narratários, a partir dos elementos contidos na narração; contudo, autor e leitor apresentam maior concretude e credenciais de cidadania, daí o seu emprego, aqui, sobretudo porque se remete a um "fora do texto".
} 


\section{O final negativo: evocação da Bíblia e da escravidão}

O último capítulo é intitulado "Das negativas"; o termo não ocorre nove vezes e outros termos de sentido negativo ocorrem seis vezes, em trecho composto por parágrafo curto. Essas negativas não têm a mesma natureza quanto ao valor; há dois grupos delas, um positivo e outro negativo, além de uma retumbante negativa final, representativa das demais.

Pode-se reconhecer um primeiro grupo, as negativas negativas - elas indicam o fracasso de Brás Cubas, sendo assim avaliadas por ele: "Não alcancei a celebridade do emplastro, não fui ministro, não fui califa, não conheci o casamento" (ASSIS, 2008. v. 1, p. 758); isso diz respeito a conquistas, a projetos de vida que agregam a quem os realiza prestígio social, fama ("celebridade do emplastro") e poder ("não fui ministro"). Com isso, a vida de Brás é só fracasso, avalizado pelo defunto que o confessa, um anti-herói. ${ }^{5}$ Se ele representa a elite patriarcal-senhorial escravagista, machista, branca, cristã, rica - há nisso considerável crítica machadiana àquela ordem social.

Esse primeiro grupo mantém o diálogo com as Escrituras, principalmente pelo fato de o narrador dizer que não experimentou o casamento, ${ }^{6}$ evocando o Gênesis bíblico. O cristianismo vê no casamento ordem divina e Brás Cubas reconhece o descumprimento desse preceito.

Reconhece-se também um segundo grupo: as negativas positivas introduzidas pela expressão "coube-me a boa fortuna de [...]", o que projeta valorização positiva para o que segue: “[...] não comprar o pão com o suor do meu rosto [...] não padeci a morte de d. Plácida, nem a semidemência do Quincas Borba” (ASSIS, 2008.v. 1, p. 758).

As duas últimas negações recuperam personagens machadianos. D. Plácida (há motivação irônica para o nome) tem aparição breve nas Memórias, mas pungente, dado o drama de sua existência. No capítulo CXLIV, intitulado "Utilidade relativa", o narrador desembucha toda a sua desfaçatez, ao comentar a utilidade relativa da vida sofrida de d. Plácida, e menciona sua morte, repelindo a trajetória de vida insignificante:

\footnotetext{
${ }^{5}$ Machado não pinta heróis, essa forma de Brás Cubas se autocaracterizar dá a dimensão, com eloquência, da envergadura humana dos personagens machadianos, que apresentam o fracasso total como única possibilidade de realização. Isso está em correspondência com o que está dito no prólogo da terceira edição, que faz referência ao pessimismo com que a obra foi escrita.

${ }^{6}$ A avalição negativa de não ter conhecido o casamento se apoia no conjunto das quatro negativas que compõem a primeira sequência. De fato, não alcançar a celebridade do emplastro, não ser ministro, não ser califa se alinham ao mesmo nível de "não conhecer o casamento"; é por esse contexto que vai aqui a avaliação em relação a essa negativa.
} 
[...] fui à casa de d. Plácida; achei um molho de ossos, envolto em molambos, estendido sobre um catre velho e nauseabundo; dei-lhe algum dinheiro. No dia seguinte fi-la transportar para a Misericórdia, onde ela morreu uma semana depois. Minto: amanheceu morta; saiu da vida às escondidas, tal qual entrara. (ASSIS, 2008, v. 1, p. 748-749)

Quincas Borba, o filósofo criador do Humanitismo, morreu demente. O tema da loucura é de grande importância na produção machadiana, como indica $O$ alienista, mas não só essa peça. Pode-se desconfiar que a negativa seja ironia, pois, no jogo de ambiguidades, a loucura poderia ser de Brás e de seu tempo. O personagem é "náufrago da existência" e "mendigo", acresce que finda a vida louco - é por isso que Brás se vê aquinhoado por não ter padecido essa desventura.

A primeira negativa do segundo grupo tem conformidade com o conjunto do livro, além de remeter às Escrituras, às avessas; este trecho do Gênesis é evocado:

3. 17 A Adão porém disse: [...] a terra será maldita na tua obra; tu tirarás dela o teu sustento com muitas fadigas todos os dias da tua vida. 18 Ela te produzirá espinhos, e abrolhos: e tu terás por sustento as ervas da terra. 19 Tu comerás o teu pão no suor do teu rosto, até que te tornes na terra, de que foste tomado: porque tu és pó, e em pó te hás de tornar. $^{7}$ (A BÍBLIA SAGRADA, 1867)

O que era visto como castigo na cena bíblica passou a ser bemaventurança na vida de Brás (e de sua classe social). Brás Cubas evitou o castigo divino, porque não comeu o pão com o suor do rosto: não trabalhou. $\mathrm{O}$ trecho toca no tema do trabalho, nas relações de produção e suas tensões sociais, em moldura bíblico-religiosa. Não trabalhar configura fuga aos ditames divinos, em desobediência religiosa, em recusa à purgação que serve como credencial para a conquista dos céus, segundo a ideologia escravista. A purgação, pregada pela Igreja, era o sofrimento imposto aos escravizados. Um de seus principais defensores foi o padre Vieira que, em um sermão de 1633, elaborou uma teologia da escravidão, da qual segue esta pequena parte:

A Paixão de Cristo parte foi de noite sem dormir, parte foi de dia sem descansar, e tais são as vossas noites e os vossos dias. Cristo despido, e

\footnotetext{
${ }^{7}$ A tradução é do Padre Antonio Pereira de Figueiredo, que Machado utilizou. Jobim (2001) registra que o autor carioca tinha essa Bíblia em sua biblioteca, em dois tomos, que agora se encontram na Academia Brasileira de Letras, encadernados em um só volume. A grafia foi atualizada.
} 
vós despidos; Cristo sem comer, e vós famintos; Cristo em tudo maltratado, e vós maltratados em tudo. Os ferros, as prisões, os açoites, as chagas, os nomes afrontosos, de tudo isto se compõe a vossa imitação, que, se for acompanhada de paciência, também terá merecimento de martírio. (VIEIRA, s.d.)

Vê-se a bem elaborada sustentação da escravidão sob o ponto de vista retórico. O sofrimento imposto aos negros escravizados pelo trabalho compulsório é um benefício! É imitação do sofrimento de Cristo. O martírio terá recompensa - não na dimensão histórica, mas no além. Apesar de chocante, essa era a convicção dominante da Igreja e dos colonizadores e servia para justificar a dominação.

Não trabalhar, então, significa escapar à maldição, sentir-se privilegiado, viver o êxtase dos bem-aventurados. E, como o trabalho é necessário, é melhor que mãos alheias o façam, na proposta de Brás Cubas, a partir de suas negativas finais. Assim, o resultado é que a maldição do texto bíblico recai somente sobre quem trabalhava - o escravizado! ${ }^{8}$

Brás Cubas morreu sem se casar, sem trabalhar, sem ter filhos transgressões bíblicas. Como ele, outros homens ricos machadianos não deixaram semente, desde o início de sua produção romanesca. Duarte aponta "a incapacidade dos senhores em gerar condições políticas e, mesmo, lideranças que garantam a continuidade do regime" (ASSIS, 2008, p. 76). Félix é órfão e não deixa filhos e, como ele, Estêvão, o Conselheiro Vale, Brás Cubas, Rubião, Quincas Borba e outros; Bento Santiago é caso à parte: tem um filho, mas o renega - o rebento vive o drama do "legado da nossa miséria". A recorrência da morte de senhores, na obra de Machado, é significativa e se expande além do drama existencial humano. Trata-se de desejo de extinção da classe patriarcal, que reproduz a miséria.

Resta ainda uma última negativa: o saldo positivo. No balanço final que faz da vida, o narrador o apura pequeno, como juiz de si mesmo: não ter tido filhos. O pequeno saldo da negativa final encerra as evocações bíblicas. $\mathrm{O}$ "legado da nossa miséria", como última expressão da obra, está em conformidade geral com os empréstimos bíblicos. Essa última negativa é o reforço derradeiro ao pessimismo assumido no prólogo do romance - em

\footnotetext{
${ }^{8}$ Machado foi acusado de ter sido omisso quanto à escravidão e de ter renegado sua condição étnica. Esse breve trecho desmente esse ponto de vista, contudo. A partir das últimas décadas do século passado, começaram a surgir, nos campos da História e da Literatura, estudos sobre o envolvimento de Machado nesses temas, como os de Chalhoub (2003) e Duarte (2008).
} 
radicalização polêmica, o mandamento da multiplicação da espécie também é perenização de miséria.

Sintetizando a apropriação bíblica nas Memórias, Maria afirma:

[...] Brás Cubas lê a Bíblia com um olhar puramente existencial, imanente, despojado de implicações religiosas, ou mesmo morais; limita-se a citá-la quando corrobora uma sua opinião, uma vivência, uma analogia. A autoridade que a Bíblia possa ter para ele é a que deriva das passagens onde encontra ressonância de visão de mundo, ou as que lhe proporcionam matéria para a criação narrativa. (MARIA, 2007, p. 13)

Todos esses elementos, nas Memórias, se combinam com a desfaçatez do narrador e apoiam seu triunfalismo inspirado nas figuras bíblicas para, no conjunto, formar e sustentar valores. A retomada da Bíblia e os vínculos narrativos sugeridos indicam duas coisas: a sanção da religião para a ordem estabelecida; e, se essa ordem tinha a benção divina, a classe representada por Brás reivindica protagonismo arbitrário.

\section{Começo e fim do romance: dimensão retórica}

Início e fim romanescos conformam a estrutura do conjunto. Devem convergir para a unidade de sentido geral e funcionar como marcas decisivas para o processo de persuasão de leitores e ouvintes, com controle da interpretação. Assim, têm dimensão retórica.

Aristóteles, um dos primeiros a sistematizar a retórica, atribuiu grande importância às partes do discurso ${ }^{9}$ (dispositio). Distinguem-se quatro, com termos diferentes em autores diversos, segundo nomenclatura grega ou latina: ${ }^{10}$

- Exórdio: tem a finalidade de expor o assunto e mover o auditório; serve para desfazer possíveis resistências (captatio benevolentiae); não é discussão da matéria, mas preparo do auditório; sua função é fática; predomina o éthos (HENRIQUES, 2013) ${ }^{11}$;

\footnotetext{
${ }^{9}$ Aristóteles discorre sobre as partes do discurso no livro terceiro da Retórica.

${ }^{10}$ Um exemplo de diferente terminologia é fornecido por Quintiliano, ao comentar a parte final de discursos judiciários, que ele chama de "Peroração", mas registra que "alguns chamam Cúmulo, outros Conclusão” (QUITILIANO, 2015, tomo 2, p. 407). A organização apresentada se aplica aos discursos do gênero judiciário.

${ }^{11}$ Henriques (2013) apoiado em Aristóteles, lembra que a persuasão resulta da combinação de três elementos vinculados à eficácia da argumentação, a partir dos termos gregos: 1) lógos (discurso racional); 2) éthos (caráter e atributos do orador); 3) páthos (emoções do auditório). Esses elementos evidenciam
} 
- Narração: exposição adequada dos fatos; deve ser racionalmente organizada e, por isso, prevalece o lógos;

- Confirmação: apresentação de provas; relaciona-se também ao lógos;

- Epílogo (peroração): recapitula o discurso, com a finalidade de tornar presente na mente dos ouvintes as teses defendidas, em proveito do orador; mobiliza as emoções (páthos).

O exórdio tem a função de indicar a direção adequada para a apreensão do sentido. O conteúdo dos proêmios não é uniforme, depende do gênero a que se filiam os discursos. ${ }^{12}$ Segundo Quintiliano, a finalidade do proêmio "não é outro, senão que preparemos o ouvinte para que nos seja mais favorável nas outras partes [do discurso]” (2015, t. 2, p. 19). Para o autor latino, no exórdio prevalece o éthos do emissor, isto é, o começo do discurso é ponto nobre para essa finalidade (QUINTILIANO, 2015, t. 2, p. 21).

Os discursos epidíticos devem ter o proêmio composto dessa forma: "[...] introduzir o tom de base e conjugá-lo com o assunto principal" (ARISTÓTELES, 2005, p. 277). É importante conduzir a atenção do ouvinte a fim de que ele pense que faz parte do elogio ou não faz parte da censura de que trata o discurso.

Os discursos do gênero judiciário têm parentesco com os poemas épicos. Ainda segundo Aristóteles, "o proêmio proporciona uma amostra do conteúdo [...], a fim de que se conheça previamente sobre o que será o discurso e que o entendimento do auditório não fique em suspenso" (ARISTÓTELES, 2005, p. 281); o que não se define não contribui para a persuasão, por causa da dispersão da atenção do auditório. O início faz com que ouvintes ou leitores acompanhem o discurso.

Proêmios do discurso deliberativo seguem as características do gênero judiciário. Para Aristóteles não têm muita importância porque, nesse gênero, o auditório tem conhecimento do assunto a ser apresentado.

Em todos os gêneros retóricos fica marcada a finalidade e importância do início: captar a atenção, apresentar a matéria, conduzir o raciocínio,

\footnotetext{
a importância das partes do ato comunicativo. Assim, os discursos persuasivos envolvem o racional, o caráter do orador e as disposições dos ouvintes: "Trata-se de considerar o que é persuasivo em cada coisa, em cada situação, sem negligenciar nenhuma delas, ou seja, o que é capaz de suscitar no interlocutor um julgamento favorável a respeito do que se propõe, uma opinião vinculada à do orador e pronta a desencadear comportamentos e atitudes desejáveis pelo proponente" (MOSCA, 2016, p. 11).

${ }^{12}$ Para Aristóteles (2005), três são os gêneros, classificados de acordo com o auditório e com a intenção: 1) Deliberativo: refere-se a assembleias políticas, para tomada de decisões referentes ao futuro, que inclui aconselhar o útil e desaconselhar o contrário; 2) Judiciário: próprio dos tribunais, ocupa-se do passado, julgando o que é dúbio ou incerto; 3) Epidítico: próprio de cerimônias solenes (alegres ou tristes); elabora elogio ou censura; refere-se ao tempo presente.
} 
controlar a interpretação, sob a marca do éthos do narrador; em alguns casos, evidencia-se também o éthos do enunciador.

A instância enunciador, primeiro nível enunciativo, é importante, pois sobre ela recai a responsabilidade pela projeção de desacordos com a instância do narrador (como ocorre em Memórias póstumas), porque, segundo Calbucci: “[...] quando enunciador e narrador não são equivalentes semanticamente, produz-se um efeito de subjetividade [...] há uma probabilidade maior de haver uma dissensão mais clara entre a instância da enunciação e a do enunciado" (CALBUCCI, 2007, p. 121). Assim, "nas narrativas em que o narrador é ator do enunciado, casos do narrador protagonista e testemunha, pode haver uma ruptura semântica entre o primeiro e o segundo nível enunciativo” (CALBUCCI, 2007, p. 124). Essa distinção é essencial para a compreensão dos papéis e limites de cada instância do processo de enunciação e para que não haja confusão entre elas.

No caso das Memórias, a narração deve ser entendida sob a senha dada já na abertura, pelo tom jocoso de brincadeira com coisas sérias (carnavalização), pela paródia de elementos sagrados (no nível do narrador). Isso diz respeito à iconoclastia, em conexão com o pessimismo declarado no prólogo da terceira edição (no nível do enunciador).

Por sua vez, o epílogo recapitula de forma breve os pontos principais da demonstração. Sua função é "tornar o ouvinte favorável para a causa do orador e desfavorável para a do adversário", principalmente no gênero judiciário. Tem-se sucesso a partir dos seguintes recursos, quais sejam: "amplificar ou minimizar; dispor o ouvinte para um comportamento emocional; recapitular" (ARISTÓTELES, 2005, p. 196).

Quintiliano afirma que a parte final deve corresponder à convergência dos principais elementos, daqueles que precisam ser alinhados, para efeito de presença na mente do auditório. O retórico latino registra que essa parte era chamada pelos gregos de recapitulação e por alguns dos latinos, enumeração; sua função é pôr "diante dos olhos a causa inteira e, ainda que tenha tido menor repercussão pelos detalhes, o conjunto adquire muito mais força (QUINTILIANO, 2015, t. 2, p. 407).

No epílogo das Memórias póstumas predomina a função de recapitulação, de forma sintética, com a ênfase em negativas, o que corresponde à técnica descrita por Quintiliano e ao tom geral da obra. Essa síntese, contudo, é carregada por amplificação, pela ênfase a negativas apontadas, inclusive, no título do capítulo final. Aliás, essa recorrência é 
prescrita por Aristóteles, que recomenda: “para que a apreensão das ideias seja efetiva, prescrevem que se proceda a muitas repetições” (2005, p. 197).

\section{Considerações finais}

Começo e fim romanescos são limites importantes que têm funções específicas na narração, inclusive de natureza retórica.

Nas Memórias póstumas, o incipit se constrói com paródia e carnavalização, num tom de "brincadeira" com coisas sagradas - o texto bíblico. A abertura da narração dá a dicção irreverente que se projeta para toda narrativa.

O fim do romance continua marcado por evocações bíblicas de forma polêmica e cumpre a função de síntese da matéria narrada, o que é feito por meio de negativas. A negativa final, retumbante e literariamente elaborada, é revestida por tom de assumido pessimismo.

A ordem social é criticada pela menção aos temas decisivos para o Brasil e o mundo do século XIX, dos quais o trabalho escravo é o mais desafiador, mencionado em uma das negativas do último capítulo. Não fica pedra sobre pedra do edifício social do Rio de Janeiro do Segundo Império; é isto que o enunciador, ao fim e ao cabo, quer demonstrar, a partir de narrativa de um de seus ilustres representantes. Tudo feito, de fato, com pleno domínio do arranjo retórico entre as partes da narração.

\section{Referências}

A BÍBLIA SAGRADA. Tradução de Antonio Pereira de Figueiredo. Lisboa: Tipografia Universal, $1867 . \quad$ Disponível em: <https://books.google.com.br/books?id $=$ YkFbAAAAQAAJ\&printsec $=$ frontcover $\& d q=$ biblia + sagrada + figueired $\mathrm{o} \& \mathrm{hl}=\mathrm{pt}-\mathrm{BR} \&$ redir_esc $=\mathrm{y} \# \mathrm{v}=$ onepage $\& \mathrm{q} \& \mathrm{f}=$ false $>$. Acesso em: $16 \mathrm{jul}$. 2020.

ARISTÓTELES. Retórica. Prefácio e Introdução de Manuel Alexandre Júnior. Lisboa: Imprensa Nacional-Casa da Moeda, 2005.

ASSIS, Machado de. Obra completa em quatro volumes. Rio de Janeiro: Nova Aguilar, 2008. 
BAKHTIN, Mikhail. A cultura popular na Idade Média e no Renascimento. O contexto de François Rabelais. Brasília; São Paulo: Editora Universidade de Brasília; Hucitec, 1987.

CALBUCCI, Eduardo. A construção do ator da enunciação em romances com narrador-personagem: a experiência machadiana em Memórias póstumas de Brás Cubas. Tese de doutorado. São Paulo: Universidade de São Paulo, 2007. 435f.

CHALHOUB, Sidney. Machado de Assis historiador. São Paulo: Companhia da Letras, 2003.

DEL LUNGO, Andrea. L'incipit romanesque. Paris: Éditions du Seuil, 2003.

DISCINI, Norma. Carnavalização. In: BRAIT, Beth. Bakhtin: outros conceitos-chave. São Paulo: Contexto, 2006. p. 53-93.

DUARTE, Eduardo de Assis. Memórias póstumas da escravidão. In: $O$ eixo e a roda. $\quad$ v. 16,2008 . Disponível em: <www.periodicos.letras.ufmg.br/index.php/

o_eixo_ea_roda/article/view/3278>. Acesso em: 19 set. 2019.

FÁVERO, Leonor Lopes. Paródia e dialogismo. In: BARROS, D.L. Dialogismo, polifonia, intertextualidade. São Paulo: EDUSP, 1994. p. 49-61.

HENRIQUES, Antonio. Argumentação e discurso jurídico. 2. ed. São Paulo: Atlas, 2013.

HUTCHEON, Linda. Uma teoria da paródia. Lisboa: Edições 70, 1989.

JOBIM, José Luiz. A biblioteca de Machado de Assis. Rio de Janeiro: Top Books; Academia Brasileira de Letras, 2001.

MARIA, Claudinei. O pão da dor e o vinho da miséria: o banquete da existência, de Jó a Brás Cubas. Dissertação de mestrado. Campinas: Unicamp, 2007. $81 f$.

MOSCA, Lineide do Lago Salvador. Entre certezas e incertezas: a racionalidade própria da retórica e da argumentação. In: (Org.). Retórica e argumentação em práticas sociais discursivas. Lisboa: Grácio Editor, 2016. p. 11-16.

PROENÇA, Paulo S. Sob o signo de Caim: Machado de Assis e a Bíblia. Tese de doutorado. Faculdade de Filosofia, Letras e Ciências Humanas. São Paulo: Universidade de São Paulo, 2011. 247f.

QUINTILIANO. Instituição oratória. Tradução, Apresentação e Notas de Bruno Fregni Bassetto. Campinas: Editora da Unicamp, 2015. 3 tomos.

SÁ REGO, E. O calundu e a panaceia: Machado de Assis, a sátira menipeia e a tradição luciânica. Rio de Janeiro: Forense Universitária, 1989. 
Machado de Assis em Linha - Universidade de São Paulo http://machadodeassis.fflch.usp.br

SCHWARZ, Roberto. Um mestre na periferia do capitalismo: Machado de Assis. São Paulo: Duas Cidades; Ed. 34, 2000.

SOUZA, Ronaldes de Melo e. O estilo narrativo de Machado de Assis. In: SECCHIN, Antonio Carlos (Org.) et. al. Machado de Assis: uma revisão. Rio de Janeiro: In-Fólio, 1998. p. 65-79.

VIEIRA, Antonio. Sermão XIV (1633). Disponível em: $<$ www.literaturabrasileira.

ufsc.br/documentos/?action=download\&id=49751>. Acesso em: 21 jun. 2018.

PAULO SÉRGIO DE PROENÇA é doutor em Letras pela Universidade de São Paulo. Dedica-se atualmente ao estudo das relações entre Bíblia e escravidão na obra de Machado de Assis. Publicou O Diabo protagonista em Machado de Assis e, em coautoria com Lineide do Lago Salvador Mosca, Revisitando Dom Casmurro: aspectos retóricos em conexão com a Bíblia.

(iD) https://orcid.org/0000-0002-1186-6438. E-mail: pproenca@unilab.edu.br.

Recebido: 08.02.2020

Aprovado: 20.07 .2020 